The Version of Record of this manuscript has been published and is available in Philosophical Psychology April 2018 http://www.tandfonline.com/10.1080/09515089.2018.1456653

\title{
Emotion as the Categorical Basis for Moral Thought
}

\begin{abstract}
I offer and develop an original answer to the question of whether emotion plays an important role in the formation of moral thought. In a nutshell, my answer will be that if motivational internalism provides us with a correct description of the nature of moral thought, then emotion plays an important role because emotion is required to explain or ground the behavioral dispositions that are involved in moral thought.
\end{abstract}

Keywords: moral judgment, emotion, motivational internalism, behavioral disposition, categorical basis

\section{Introduction}

Does emotion play a role in the formation of moral thought? Many working in moral psychology have been impressed enough by the empirical data to answer in the affirmative. Two bodies of research have been especially influential. To begin with, a number of studies found that when emotions are induced moral judgments tend to be affected. For example, participants hypnotized to feel disgust in response to certain words were found to make more negative evaluations of morally neutral vignettes containing the words in question than participants not hypnotized to feel disgust (Wheatley and Haidt, 2005; see also, Greene and Haidt, 2002; Schnall et al., 2008; Horberg et al., 2009). Other studies have shown how inducing anger led participants to make more severe moral judgments of people guilty of wrongdoing who had escaped punishment (Goldberg et al., 1999). ${ }^{1}$ And the second body of research pertains to psychopaths. Not only are psychopaths known to suffer from pronounced emotional impairments (Cleckley, 1941; House and Milligan, 1976; Blair et al., 1997), but there is evidence also to suggest that psychopaths cannot understand moral concepts such as right and wrong (e.g. Blair, 1995), leading many theorists to infer that psychopaths' lack of moral insight is due to problems in emotional processing (Haidt, 2001; Nichols, 2002; Prinz, 2007).

So, it is a pressing concern for those relying on such data that there is reason to think the empirical base is not as solid as many supposed. To begin with, some authors complain that the emotion-induction findings have been over-interpreted. For instance, Joshua May (2014) has argued that the studies on disgust do not show disgust substantially influencing moral thought, and a more parsimonious reading of the literature is that disgust only sometimes slightly influences moral thought. Others have claimed that alternative explanations for the formation of moral thought are not ruled out by the evidence. So, perhaps

\footnotetext{
${ }^{1}$ There is evidence also to show that the induction of positive or pleasurable emotions can influence moral thought (Valdesolo and DeSteno, 2006; Aquino et al., 2011; Strohminger et al., 2011; Pastötter et al., 2013).
} 
emotion merely directs people's attention to morally relevant features, rather than directly bring about a change in moral thought (Huebner et al., 2009). And as regards the body of evidence relating to psychopaths, although some earlier studies found that psychopaths cannot distinguish moral transgressions, such as hitting people, from conventional violations, such as spitting or dressing in opposite sex clothes (Blair, 1995; Blair et al., 1997), more recent studies cast doubt on earlier findings (Dolan and Fullam, 2010; Cima et al., 2010; Aharoni et al., 2012). For instance, Aharoni and colleagues (2012) found that when instructed to select from a list of moral and non-moral violations acts rated as morally wrong by members of society, psychopaths performed no worse than normal controls.

Now, to be clear, none of these criticisms rule out the idea that emotion has a role to play in moral judgment. Thus, even if the induction of emotion has minimal effect on participants' moral judgments, emotion might still be involved in the formation of moral thought. For the fact of emotion having a minimal effect would show at most that emotion might not always be sufficient for moral thought, which is consistent with supposing that emotion might play an important role in the sense that without emotion moral thought may not be possible. Agreed, this would threaten to rule out the view that emotions are to be identified with moral judgments, but it would not exclude a non-identity view, according to which emotions are necessary but not sufficient for moral judgment. Moreover, even if emotion can make the moral features of a situation salient to us, this again fails to show that emotion is not needed for moral thought. This is because, first, for all we know it is only emotion that makes the morally relevant features of a situation evident to us. So, perhaps without emotion there would be nothing to inform moral thought. Second, and more plausibly, in my view, emotion might be needed for moral thought after we register the morally relevant features. For we still need to get to the moral judgment once we have registered the morally relevant features, and it remains a live hypothesis that emotion plays an important role in bridging this gap for us. And, finally, with respect to psychopaths even if more recent evidence supports the idea that psychopaths can make moral judgments, this fails to show that emotion plays no role in moral thought, since psychopaths might not be emotionally impaired in a way that prevents them from making moral judgments. Moreover, doubts will continue to be had as to whether psychopaths are able to make genuine moral judgments. As often pointed out, psychopaths behave persistently in ways that fail to serve moral ends, a fact that many take to be inconsistent with the idea that to make a sincere moral judgment (as opposed merely to an 'inverted commas' one: see Hare, 1952) requires being motivated to act in accordance with the moral judgment. So, in other words, it might be argued that even if psychopaths are able to select those acts rated as morally wrong by members of society as the Aharoni and colleagues' study suggests, this fails to show that psychopaths properly understand the moral concepts in question (cp. Morse, 2008).

Nevertheless, there does seem to be sufficient reason to think the current empirical base is not enough to establish that emotion has a role in moral thought. Moreover, even when more evidence becomes available there are likely to be questions regarding how to interpret the evidence, and what if anything it tells us about the relationship between emotion and moral thought. But, perhaps there are other 
considerations that support the view that emotion plays a role in the formation of moral thought. Indeed, I want to advance an original argument for that view that is largely philosophically, not empirically, informed. My core claim will be that if motivational internalism provides a correct account of the nature of moral thought, then good reason exists to think that emotion has a key role in the formation of moral thought because emotion is needed to explain the behavioral dispositions involved in moral thought. Strictly speaking, then, my argument will be a relatively modest one, insofar as the success of the argument will require motivational internalism to be true, and there is not the space to defend that view here. That being said, motivational internalism is a highly respected view, and, therefore, if that view is committed to assigning a role to emotion as regards the formation of moral thought, then I take that to be a strong argument for the idea that emotion plays an important role after all.

The structure of the paper is as follows. In §2 I explain why motivational internalism requires there to be some intrinsic property that grounds or underlies moral thought. In $\S 3$ I reject a number of potential contenders for that property. Then in $\S 4$ I give the positive case for emotion being the best candidate for the property in question. Finally, in $\$ 5$ I say why regarding emotion as that property underlying moral thought is able to avoid a number of objections that have been made to the idea that emotion is involved in the generation of moral thought.

\section{Motivational internalism and the need for a categorical basis}

Let motivational internalism be understood as the thesis that motivation is internal to moral thought in that to think sincerely we ought to do something is (at least in part) to be motivated to do that thing (Smith 1994). ${ }^{2}$ This is not to say that motivational internalism is the view that moral thought need be sufficient for action, however. Motivational internalism admits of both stronger and weaker versions. According to the stronger version, the making of a moral judgment is sufficient for performing (or at least attempting to perform) the action that is in accordance with that moral judgment. According to a weaker version, however, a person need be motivated only to some degree to act in accordance with the moral judgment to count as making that judgment. Many internalists today consider the weaker version to be the better one because it allows for cases where people make moral judgments but have stronger non-moral motivations that determine action, and likewise I assume the weaker version in what follows.

There is also a distinction to be drawn between cognitivist and non-cognitivist forms of motivational internalism. According to the cognitivist version, moral judgments are or involve belief

\footnotetext{
${ }^{2}$ Sometimes motivational internalism is held only to be the thesis that motivation is necessary for moral thought. Understood as such the view leaves open the possibility that motivation necessarily accompanies moral thought without constituting it (Tresan, 2006, Bjornsson et al., 2015). However, in this paper I interpret motivational internalism in the stronger constitutive way, which does seem to be how internalism is more commonly understood (see e.g. Nagel, 1970; Mele, 1996; Zangwill, 2003).
} 
states, whereas according to the non-cognitivist version, moral judgments are more akin to desire states. Proponents of non-cognitivist versions of motivational internalism often draw on a Humean theory of motivation to defend their view. According to the Humean view of motivation, belief states have no motivational power of their own, possessing solely a mind-to-world direction of fit. Therefore, if moral judgments are motivating in and of themselves, then they must be non-cognitive states, namely desire-like states (see Blackburn, 1998 for a classical defence). Proponents of the cognitivist version of motivational internalism reject the Humean theory of motivation. They argue that motivation can be internal to belief states or at least certain sorts of belief states (see Nagel, 1970; McDowell, 1979; McNaughton, 1988). Although my own thinking is that the Humean theory has it right and that, therefore, moral judgments must have a desire-like character if motivational internalism is true, ${ }^{3}$ it is not clear that anything of importance rests on this insofar as the main argument of this paper is concerned. Indeed, it seems to me that for reasons to be explained shortly, both cognitivist and non-cognitivist forms of internalism - along, we might add, with so-called hybrid theories, according to which moral judgments are compound states comprising desires and beliefs (e.g. Ridge, 2006) - will be committed to assigning one and the same role to emotion as regards the formation of moral thought.

And there is reason to think that motivational internalism gives a compelling account of the nature of moral thought. In particular, it is unclear what we would say of someone who claims they ought to do $A$, but is not motivated to do $A$. In such a case, we are likely to doubt the person's sincerity or insight into what they believe to be morally right or whether they know what they are saying when they claim it is right to do $A$. Moreover, motivational internalism can seem plausible on phenomenological grounds. For arguably part of what it is like to think something is right or ought to be done is to feel moved or motivated to do that thing. Horgan and Timmons make this point when they speak about moral judgment involving a felt 'to-be-done-ness' (Horgan and Timmons, 2000, p. 129).

There are those who reject motivational internalism, of course (e.g. Brink, 1989; Svavarsdottir, 1999; Zangwill, 2003). Motivational externalists hold that we can think we ought to do $A$ but not be motivated to do $A$. For the motivational externalist, then, moral thought is insufficient on its own for someone to be motivated to act in accordance with moral thought. In addition, a separate desire is needed. In defence of their position externalists often appeal to amoral individuals who might seem to make moral judgments but lack the appropriate motivation (Brink, 1989; Svavarsdottir, 1999; Zangwill, 2003). This, in turn, invites standard motivational internalist replies, such as denying that amoral people make genuine moral judgments - for if they were making sincere judgments then necessarily they would be motivated to act in accordance with those judgments (for one recent defence of this sort of internalist response, see Bromwich, 2016) - or accepting these people are making genuine moral judgments but claiming they are

\footnotetext{
${ }^{3}$ Thus, it is possible to accept a Humean theory of motivation but not be a motivational internalist. Indeed, that is the view of motivational externalists who accept both a Humean theory of motivation along with the view that moral judgments are bona-fide belief states (see, for instance, Zangwill, 2003).
} 
motivated (albeit very weakly, perhaps) to act in accordance with those judgments. Unfortunately, it is not possible to do justice to the debate between the internalist and externalist here. ${ }^{4}$ Therefore, having noted the disagreement, I will proceed as if motivational internalism were true. For notwithstanding dissenting views motivational internalism is an influential and widely-held view for the sorts of reasons spelt out above, and is certainly a serious enough view for the purpose of exploring its implications for the relationship that might hold between emotion and moral thought.

So, assuming the truth of motivational internalism, what might the relationship between emotion and moral thought be? To understand how emotion might relate to moral thought, notice that common to both cognitivist and non-cognitivist versions of motivational internalism, is the view that our moral judgments are or involve behavioral dispositions. ${ }^{5}$ This is because both cognitivist and non-cognitivist versions of motivational internalism hold that to form a moral judgment is to be motivated to act in accordance with the moral judgment, which is equivalent to saying that to form a moral judgment is to be disposed to act in accordance with the moral judgment. As Bjornsson and colleagues put the point, for the motivational internalist "forming a moral judgment seems to go beyond or to be other than registering that some fact obtains: At the very least it additionally involves forming a disposition to perform a certain action" (2015, p. 2; see also Doris and Stich, 2007). Thus, the person who is not motivated to do $A$ is the person who is not disposed to do $A$, and the person who is only weakly motivated to do $A$ is the person who is only weakly disposed to do A. Now, admittedly this picture most naturally fits the idea that moral judgments are desire-like states - for it is widely, if not universally, accepted that desires are or comprise behavioral dispositions, that to desire to do $A$ involves being disposed to do $A$ or, at least, being disposed to do those things that one believes will bring about the doing of $A$ (see Stalnaker, 1984; Smith, 1994;

\footnotetext{
${ }^{4}$ It might be remarked that there is a legitimate question as to whether that debate will ever be easily resolved given that much of the disagreement between the internalist and the externalist seems to come down to a difference in understanding of what counts as making a genuine moral judgment (cp. Bromwich, 2016).

${ }^{5}$ My own view is that motivational internalists should probably claim that moral judgments are behavioral dispositions. However, I will often speak of motivational internalism as the view that moral judgments are or involve behavioral dispositions so to accommodate versions of internalism that consider moral judgments to be compound, comprising behavioral dispositions and other mental properties. But see fn. 9 for brief discussion of one possible motivation for thinking moral thought contains something in addition to behavioral dispositions.
} 
Blackburn, 1998; Ashwell, 2014; Hyman, 2014) ${ }^{67}$ - but again it needn't rule out cognitivist versions of internalism if certain kinds of belief states can also comprise dispositions to behave in certain ways. ${ }^{8} 9$

According to the motivational internalist, then, forming a moral judgment involves forming certain behavioral dispositions, where depending on the motivational internalist's broader meta-ethical framework these dispositional properties or powers of ours might be taken to be desire-like states or a certain kind of belief state. However, interpreted as the view that moral judgments comprise behavioral dispositions, motivational internalism is wholly silent regarding the identity of the properties that might underlie or bestow on us our behavioral dispositions. In other words, motivational internalism tells us nothing about what it is in virtue of which a person forms their moral beliefs along with their desires and other behavioral dispositions. The point relates to a much more general one regarding dispositional properties, namely that the dispositional properties of objects do not come along ready-made, so to speak. That is to say, objects are not disposed to behave one way rather than another way for no reason at all. To put the point in a way that is familiar in the academic literature, it is widely recognised that there has to be some underlying or intrinsic fact about or property of an object in virtue of which the object has its dispositional properties or powers. This intrinsic property of the object is commonly referred to as the

\footnotetext{
${ }^{6}$ The idea that desires are behavioral dispositions is not universally endorsed, but it is the most widely accepted view (cp. Ashwell, 2014; Schroeder, 2015), and I assume it to be true in what follows in the paper. Very briefly though, my own reason for endorsing that view is that I think it describes correctly the phenomenology or whatit-is-likeness of desire. That is to say, I think that what it is like for us to desire to do something is for us to feel motivated or disposed to do that thing (on this point, see also Ashwell 2017a)

${ }^{7}$ Indeed, Simon Blackburn, a prominent defender of non-cognitivism, writes: "To hold a value, then, is typically to have a relatively stable disposition to conduct practical life and practical discussion in a particular
} way." (1998, p. 67)

${ }^{8}$ Which again they cannot if the Humean theory of motivation is true. Since nothing hinges on this insofar as the main argument of the paper is concerned, I will say nothing more on the subject.

${ }^{9}$ How is the motivational internalist to explain the occurrent nature of much of moral thought if, as internalism implies, moral judgments involve behavioral dispositions? One response the internalist might give is to say that moral thought's occurrent nature is to be explained by moral thought's other components. For instance, perhaps a moral judgment comprises a behavioral disposition and a registering of some fact (Bjornsson et al., 2015). An alternative response, however, might simply be to say that behavioral dispositions can themselves be occurrent states. And certainly, behavioral dispositions often bear the hallmarks of occurrent mental states. For instance, behavioral dispositions can have a distinctive phenomenology. Thus, there is often something it is like to be disposed or motivated to behave in certain ways (see also, fn.6). Also, behavioral dispositions can be active in that they can exercise causal influence on our behaviors. Indeed, it can be argued that behavioral dispositions just are mental states the nature or essence of which is to cause us to behave in particular ways when certain circumstances obtain. And, if behavioral dispositions can be occurrent states then there will be no need to posit anything in addition to the behavioral disposition to explain moral thought's occurrent nature. 
categorical or causal basis of the disposition. Consider a glass which is disposed to shatter in response to being struck with force in virtue of its microphysical structure (Prior et al., 1982; Lowe, 2008; Choi and Fara, 2014) - the microphysical structure of the glass being the categorical basis for the disposition of a glass to shatter in the event of being struck with force. ${ }^{10}$

\section{Some unsuitable candidates for the categorical basis}

What, in the case of ourselves, might play the role of a categorical basis for our behavioral dispositions, including our moral judgments and desires? ${ }^{11}$ Now, a strong case can be given for thinking the categorical bases must be distinct from the behavioral dispositions themselves. That is to say, sound reasons exist for thinking our behavioral dispositions cannot serve as their own categorical bases. One reason is that grounding or in-virtue-of relations - such as that holding between dispositional properties and their categorical bases - are standardly held to be irreflexive, never holding between entities and themselves. In other words, a widely held view is that nothing is able to ground or underlie or explain itself. ${ }^{12}$ This isn't to rule out the idea that there might be things that do not depend for their existence on anything. However, as Tuomas Tahko points out, if there are any such things, we tend to think of them as being 'primitive', which is to say they are entities that are not grounded in anything at all (Tahko, 2015). And, certainly, it seems right to say that the in-virtue-of relation holding between our behavioral dispositions and their bases is irreflexive. After all, to say that I am disposed to do something - say, go for a walk or watch some news channel - in virtue of my being disposed to do that thing seems to make little sense. Another reason for thinking that our behavioral dispositions cannot serve as their own bases, is that it is commonly supposed that dispositional types are 'multiply realizable' in that dispositional properties can

\footnotetext{
${ }^{10} \mathrm{We}$ need not debate whether all dispositions have categorical bases. Even if the dispositional properties of such things as fundamental physical particles (electrons, say) lack categorical bases (but see Williams, 2011 for critical discussion), I am talking in the main text about the dispositional properties of those everyday objects where the search for categorical bases seems wholly warranted.

${ }^{11}$ In what follows in the main text, I will assume that when we ask in virtue of what are people or human beings disposed to behave in the ways they do - say, to travel to work, or to help those in need, or to do terrible things to one another in times of war - we are essentially after a psychological explanation of some kind, that is, one that refers us to certain facts about human nature, or the individual natures or psychologies of the people in question. (Lowe, 2008; Mayr, 2011). Of course, if mental states are, or supervene on, physical states, then holding that behavioral dispositions have psychological properties as their bases will be consistent with perhaps entail, even - holding that behavioral dispositions have physical properties as their categorical bases. ${ }^{12}$ Although the idea that grounding is an irreflexive relation has some detractors (e.g. Jenkins, 2011), it is a widely held view (e.g. Fine, 2001; Schaffer, 2009; Audi, 2012), and, as I go on to say in the main text, it seems a very plausible view regarding the relation holding between our behavioral dispositions and their bases.
} 
have a variety of bases (Prior et al., 1982). To borrow an example from Choi and Fara (2014), some objects are fragile in virtue of their irregular atomic structure and others in virtue of their weak intermolecular bonding. But, if the properties underlying the same dispositional types can be diverse, then they cannot be identical to the dispositions they underlie; for if they were identical they would not be diverse after all.

Still, might our behavioral dispositions have behavioral dispositions other than themselves as their bases ${ }^{13}$ For instance, might my desire to know the news together with my believing a certain news channel to be a reliable news source, ground or explain my disposition to watch the news channel in question? For this idea to work it will be necessary for the behavioral disposition that serves as a basis to be distinct from the behavioral disposition it allegedly underlies, since otherwise we will be saying that behavioral dispositions underlie themselves, and that possibility has been ruled out already. And therein lies a major challenge for the view that our behavioral dispositions have other behavioral dispositions we possess as their bases. This is because it is very difficult to conceive of suitable behavioral dispositions that are distinct from the dispositions they supposedly underlie. Consider the example just given. What is it to desire to know the news? On a dispositional theory of desire, it will be something like being disposed to do those things one believes will result in coming to know the news, including watching a certain news channel. But, in which case, a desire to know the news cannot underlie the behavioral disposition in question because a desire to know the news comprises the behavioral disposition in question. That is to say, my desire to know the news will just involve my being disposed to watch a certain news channel in the event of my thinking the news channel to be a reliable news source ${ }^{14}$ Hence, to the question of why I am disposed to watch a news channel in the event of thinking it will give me knowledge of the news, it would be no good to answer that I desire to know the news. That we know already. What we are wanting to understand is why, or in virtue of what, I desire to know the news, where an answer to that question will necessarily refer us to some property I bear that is wholly distinct from the behavioral disposition that makes up that desire of mine. But, unless a suitable behavioral disposition playing the role of that property can be found - and, again, it is unclear what that might be - then it cannot be the case that my behavioral disposition has another behavioral disposition as its basis. ${ }^{15}$

\footnotetext{
${ }^{13}$ I thank an anonymous reviewer for raising this question.

${ }^{14}$ Notice, as well, how my believing a certain news channel to be a reliable news source enters into the characterization of the behavioral disposition in question (namely, as a stimulus condition for the manifestation of the disposition) and, therefore, is also not suited to serve as a basis for that behavioral disposition of mine. The idea that beliefs and other mental representations serve as stimulus conditions for the manifestation of our behavioral dispositions will be developed further in the main text.

${ }^{15}$ There are also deeper worries of a more metaphysical kind with the idea that behavioral dispositions have behavioral dispositions as their bases, and which, if well founded, would mean that the search for a behavioral disposition that grounds other behavioral dispositions will indeed be a hopeless one. For instance, it is sometimes pointed out that dispositions seem to be relational properties holding between objects and the
} 
The upshot of the above is that our moral judgments and desires do not seem like good candidates for the properties that serve as bases for our behavioral dispositions, which is just to imply that moral thought itself cannot underlie our dispositions to behave in accordance with moral thought. But neither are our cognitive and perceptual representations of natural or non-moral features of the world good candidates. To be sure, such mental states do not seem to be or involve behavioral dispositions, ${ }^{16}$ and so in that regard they might be considered better suited to serve as bases than desires and moral judgments. However, such mental states are still poor candidates for the categorical bases. And this is because I think the question of what it is in virtue of which we are disposed to behave in some way is typically the question of what it is in virtue of which we are disposed to behave in some way in response to our cognitive and perceptual representations of the world - in the same way the question of what it is in virtue of which a glass is disposed to shatter is typically taken to be that of what it is in virtue of which a glass is disposed to shatter in response to being struck. In the typical case, then, we form some mental representation of the world (say, of some other person being injured) in response to which we find we are disposed to behave in a certain way (say, to assist the other person). But, this doesn't tell us why we are disposed to behave in a certain way when we form the mental representation in question. Thus, it would be no good to say we are disposed to assist some other person in response to our representing them to be injured in virtue of our representing them to be injured, since we want to know why we are disposed to behave in this way when we represent someone to be injured. And, of course, not everyone would be disposed to assist another person in the event of representing them to be injured - the psychopath might not be disposed in this way,

manifestations of the dispositions. But, it can be plausibly argued that objects have the relational properties they do only in virtue of their non-relational or intrinsic properties, that is, those properties that inhere in and characterize the objects that stand in relations to other things (Russell, 1927; Chalmers, 2010). For example, we might say that physical object, $x$, is larger than physical object, $y$ - thus, stands in the larger-than-y relation - solely in virtue of some intrinsic property of $x$, namely, x's size. Similarly, we might say that I stand in the being-disposed-to-watch-the-news relation solely in virtue of some intrinsic or non-relational property of mine, namely, whatever property it is in virtue of which I am disposed to watch the news. But, if that is the case (and there is not the space to provide a defence of that idea here, hence the reason why it is not part of my argument in the main text), then behavioral dispositions cannot have behavioral dispositions as their bases because all behavioral dispositions are relational properties, and, therefore, unsuited to play the role of categorical bases. ${ }^{16}$ Thus, it seems possible to perceptually or cognitively represent the world in some way and not be disposed to behave in any way (on this point, see also Ashwell, 2017b). Also, phenomenologically-speaking I think perceptual and cognitive representations do not present themselves to us as being behavioral dispositions. For example, I think there is nothing to my perceptual experience of a red apple in front of me or my judging there to be a red apple in front of me, that involves my being or feeling disposed to behave in any particular way. 
for instance. But in which case, the difference between the person who is so disposed and the person who is not must be due to some feature of them both that is distinct from their representations of the world.

What might that property be? What is that property we have that might confer on many of us a disposition to assist other people in the event of our thinking them to be injured, but which is missing from the psychopath, say? We have eliminated from consideration our behavioral dispositions, including desires and moral judgments, along with our mental representations of natural or non-moral features of the world (which serve as the stimulus conditions for the manifestations of our behavioral dispositions). So, what are we left with? I can think of two remaining candidates only that might be suggested for the categorical basis for our moral judgments and other behavioral dispositions. To begin with, it might be suggested the categorical basis comprises some innate moral code, that is to say, a code consisting of innate or inborn knowledge of various moral rules and principles of action (see Harman, 2000; Hauser, 2006; Mikhail, 2007; Dwyer, 2009). Two reasons commonly given for the existence of such a moral code are as follows. First, an innate code is sometimes posited to explain why people often make moral judgments about certain novel cases rapidly and intuitively, but in a way that seems to comply with often quite sophisticated moral rules or principles. For instance, people tend to deliver moral judgments about so-called 'trolley cases' without much conscious deliberation. All the same, their judgments appear to conform with various moral principles, such as the doctrine of double effect, according to which it can be permissible to do something good (e.g. divert a trolley away from five innocents) that has an evil side effect (e.g. death of another innocent) so long as the side effect is unintended. A number of authors infer from this that there has to be some innate moral code that forces people to evaluate human action in terms of its moral structure, but with no conscious awareness. Second, it is alleged that people's moral judgments regarding certain cases tend to be the same irrespective of such factors as upbringing and culture. For instance, regardless of background people tend to agree it is morally acceptable to divert a trolley away from five innocents toward one innocent, but unacceptable to push an innocent in front of the trolley with the same outcome in terms of life saved and lost (Mikhail, 2007). Again, it is inferred this feature of moral thought can be explained by supposing the principles people use in different situations are part of an innate moral code, and, therefore, insensitive to upbringing and cultural background.

However, there is good reason to reject the idea that an 'innate moral code' can serve as a categorical basis for the behavioral dispositions involved in moral thought. This is because any such moral code would itself seem to be nothing more than a collection of behavioral dispositions in need of a categorical basis. For, on the face of it, a moral code consisting of knowledge of moral rules or principles of action is nothing other than a collection of beliefs regarding those rules or principles that govern behavior, which, in turn, seems to be nothing other than a bundle of moral beliefs or, in other words, a bundle of beliefs regarding how we ought to behave (that we ought to behave in ways that maximise utility, or in ways that treat people as ends, not solely as means, for instance). And what is a collection of moral beliefs on the motivational internalist framework? Answer: a collection of behavioral dispositions. 
But if innate moral codes are behavioral dispositions, then they cannot explain or underlie our behavioral dispositions. Consequently, the categorical basis for moral judgment cannot be some innate moral code.

Now, in response someone might argue that not all parts of an innate moral code need comprise behavioral dispositions. For example, someone might hold that beliefs about who is morally considerable need not dispose anyone to any particular behavior, at least until other beliefs are added to it. But, in reply, two things can be said. First, it is far from clear that beliefs about who is morally considerable (say) are not behavioral dispositions on the motivational internalist framework. This is because if motivational internalism is true, then it is difficult to see what thinking someone is morally considerable could be other than being disposed to behave toward that person in certain ways, say, in ways that seek to protect that person in the event of believing them to be under attack. Therefore, if an innate code comprises nondispositional elements, then a better example to show this is likely to be needed, and it is not obvious what that might be. Second, even if it were the case that certain elements of a moral code are not behavioral dispositions, clearly a very large part of the code will have a dispositional character on the motivational internalist framework, since such a code is supposed to consist of innate knowledge of moral rules or principles of action. Indeed, the idea that innate rules and principles of action can account for moral thought in situations such as those described by trolley cases, is what makes the innate moral code hypothesis an attractive one for some theorists (Harman, 2000; Hauser, 2006). But, if innate knowledge of moral rules and principles make up a substantial part of the moral code, then that would seem sufficient to disqualify such a code from serving as a basis for the behavioral dispositions involved in moral thought.

And, note, that if an innate moral code does not underlie moral thought, then an innate code cannot be responsible for those properties of moral thought that believers in an innate code assign to moral thought, namely, moral thought's universality and tendency to be formed rapidly and with minimal reflection. I make the point because it suggests an important desideratum for a successful account of the categorical basis, namely, that that account needs to explain these two features of moral thought. As I will show in the next section, it counts strongly in favour of what I believe to be the only remaining candidate for a categorical basis for moral judgment that that candidate has the resources to explain such properties.

\section{Emotion as the categorical basis}

The candidate in question is emotion, and I now outline several considerations supporting the idea that emotion serves as the categorical basis for moral thought and other behavioral dispositions. To begin with, it should be remarked that emotions seem to have the right sorts of properties to act as categorical bases. Even though many emotion theorists refrain from saying that feelings - of the psychic or bodily form exhaust emotion, many accept that feeling makes up a large and important part of emotion (James, 1884; Blackburn, 1998; Prinz, 2004; Whiting 2011, 2012), and it is plausible to suppose that different emotions confer on us different behavioral dispositions in virtue of their characteristic feel. So, we might say it is in virtue of anger's irritable or incensed felt quality that anger confers on us the behavioral disposition 
involved in the belief that someone has wronged us, say, or it is in virtue of fear's edgy quality that fear bestows on us the behavioral disposition involved in evaluating something is to be avoided, for instance.

There is reason, then, to think emotion has the right sorts of properties to act as a categorical basis. But can positive reasons be given for thinking emotions do act as bases for our behavioral dispositions? The following considerations answer that question in the affirmative. First, that idea is suggested by reflection on certain cases. For instance, it is suggested by the example of the psychopath considered earlier in the paper. I have explained why such things as beliefs and desires are not good candidates for explaining the difference in behavioral disposition between the psychopath and non-psychopath. What, then, might account for the difference? It is a compelling thought that the difference in behavioral disposition between the psychopath and non-psychopath is due to a difference in emotion. Thus, it seems plausible to suppose that many of us are disposed to assist other people in the event of seeing them injured because seeing people to be injured distresses us, whereas the psychopath fails to be similarly disposed because witnessing such things doesn't emotionally affect them in this way.

Second, that idea is borne-out anecdotally or by first-person experience. The point is that when we are disposed to do something we are often aware of this behavioral disposition of ours having its basis in emotion. For instance, we see that in virtue of finding some odour disgusting we want to avoid the odour, or that in virtue of feeling distressed by someone's injury or misfortune we are disposed to assist the other person, or, that in virtue of taking pleasure in knowing the news we are disposed to watch a trusted news channel. Now, it need not always be the case we are aware of the emotional bases of our behavioral dispositions. The emotions in question might be of a weak or faint nature and barely perceptible (they are 'calm passions', as Hume might have put it), or we might not be paying attention to the emotions underlying our behavioral dispositions. But, we are often aware of there being such bases, and that suffices to provide solid support for the idea that emotions are the categorical bases for our behavioral dispositions. And again, note we are not similarly aware of desires and beliefs serving as categorical bases for our behavioral dispositions. We are not aware of desires serving as categorical bases because these are the very things that require explanation, and we are not aware of beliefs acting as categorical bases because we are aware of these as being stimulus conditions for the manifestations of our behavioral dispositions.

Third, the idea that emotion is the categorical basis for our behavioral dispositions receives support from the empirical literature. Antonio Damasio's work in particular suggests that people who have suffered loss of emotion resulting from brain injury are unable to choose between different options of action available to them in virtue of failing to 'somatically mark' the different options (Damasio, 1994). It seems no course of action elicits in these people much emotion (excitement or anxiety, say), and as a result their dispositions to action are severely attenuated. The findings are a compelling source of evidence because not only do they strongly suggest that emotions underlie or explain our behavioral dispositions for where there is no emotion there is no disposition to action - but they give solid support also to the idea that our behavioral dispositions have their bases in emotion and nothing else. For it is a striking feature of 
these people that their cognitive and other non-emotional capacities are mostly intact, and yet this makes no or little difference to how they are disposed to act.

The final consideration I want to give in favor of the view that emotion is the categorical basis is that that view has the resources to explain why moral thought seems to possess some of the features that believers in an innate moral code assign to moral thought. First, it can explain the universality of moral thought because to the extent to which moral thought is universal this can be explained by the fact that people are sufficiently similar in how they respond emotionally to the world so to have similar behavioral dispositions. Thus, if people are wired-up emotionally to the world in similar ways - where that might be the result of evolution and/or the influences people tend to have on each other (see Haidt, 2001) - then it should be no surprise if they have by and large similar behavioral dispositions, and, therefore, make similar moral judgments. Second, viewing emotion as the categorical basis for the behavioral dispositions involved in moral thought can explain why people tend to form moral judgments about novel scenarios intuitively and often with minimal reflection. On the view I am defending, they do this in virtue of the emotions that consideration of the scenario induces in them (on this point, see also Haidt, 2001; Greene et al., 2001; Greene, 2007). For instance, it is in virtue of the anxiety or discomfort that reflection on certain trolley cases causes us that we form the behavioral dispositions involved in thinking that the behaviors in question are impermissible. Moreover, we can explain why these judgments conform to certain moral principles. They do this not because they are explained by these moral principles of action, but rather because the behavioral dispositions that our emotions underlie tend to fit these principles of action (on this point, see Nichols, 2005). For instance, my aversion to pushing an innocent in front of a trolley explains the behavioral disposition that is involved in my thinking pushing innocents in front of trolleys is wrong. Now, that behavioral disposition fits a number of moral rules, including a rule prohibiting treating people as means to ends. However, it is my aversion to killing and not my employment of the rule that is responsible for the moral judgment I make. To be sure, the fact the moral judgment fits the rule makes it appear as if the moral judgment is explained by the employment of the rule (and, indeed, post hoc rationalisation may lead me to think the moral judgment is to be explained in this way: see Haidt, 2001, who refers to this as the 'wag-the-dog illusion'), ${ }^{17}$ but in reality, the moral judgment merely accords with the rule and is explained by the emotion that was induced in me.

\section{Further supporting considerations}

In this penultimate section, I will show how viewing emotions as the categorical bases for the behavioral dispositions involved in moral judgment is able to answer a number of objections to the idea that emotion

\footnotetext{
${ }^{17}$ Thus, Haidt writes "[the] illusion can be called the wag-the-dog illusion: We believe that our own moral judgment (the dog) is driven by our own moral reasoning (the tail)." (Haidt 2001, p. 823)
} 
plays a role in moral thought. As we shall see, answering these objections will help to consolidate the view that I am advancing, as well as elucidate some important features of that view.

First, consider the objection that moral thought doesn't involve emotion because it is possible to undergo an emotion without making a moral judgment. For instance, I can feel disgusted by some behavior - the eating of earwax, say - without thinking a moral violation has been committed (Hauser, 2006; May, 2014). Now, I think this is a strong objection to any view that takes emotion to be sufficient for moral thought, including the view that moral judgments are emotions. However, it is no part of the claim that emotion serves as the categorical basis for moral thought that emotion is sufficient for moral thought. Although our behavioral dispositions have emotions as their categorical bases, this doesn't mean our emotions need always confer on us behavioral dispositions. Indeed, I take it that whether an emotion succeeds in disposing a person to behave in some way will depend on other factors, including further facts regarding that person's psychology. For instance, if I have a strong aversion to the idea of berating a person who eats earwax, or the belief that what they are doing is neither harming anyone nor being done with malevolent intent, then I might be less likely to be disposed to rebuke such a person despite the fact that what they have done causes an unpleasant visceral reaction in me. In such a case a pang of disgust can fail to confer on me a behavioral disposition it might have done due to the presence of some other mental state. ${ }^{18}$ It might also be the case an emotion confers on a person a behavioral disposition but the disposition doesn't qualify as a moral judgment (see Blackburn, 1998, who distinguishes between simple preferences and those states of mind where we are ready to put pressure on others who threaten to not comply with norms we consider fundamental, suggesting only the latter sorts of mental states qualify as moral thinking, where a mental state takes on an imperative character, so to speak).

Second, consider the objection that emotion doesn't play a substantial role in moral thought because dispassionate moral thought is possible. For instance, I can believe I ought to do something - say, give to charity - even though I am not presently undergoing an emotion. Now, supporters of the view that emotion plays an important role in moral thought could reject what is being claimed here. Thus, possibly we are undergoing an emotion in such cases, only the emotion in question is faint and difficult, perhaps impossible, to detect. I think we would have to respond in this way if the claim being advanced were that moral judgments are emotions or have emotions as constituents. For then we would seem committed to

\footnotetext{
${ }^{18}$ This suggests a reason why in a study conducted by Fiery Cushman (2008), study participants were found not to impute blame to people who maliciously attempted harm but where harm occurred outside people's causal responsibility, but imputed blame to people who maliciously attempted harm but where no harm occurred. In both types of cases, it might be surmised that a malicious harm attempt triggered a negative emotion, such as anger or displeasure. But whereas in the second type of case, the emotion, unimpeded by other mental states, succeeded in disposing participants to impute blame or punishment despite no harm actually occurring, in the first type of case, the emotion failed to dispose participants to impute blame due to a belief that harm occurred outside people's causal responsibility (see also, Trémolière and Djeriouat, 2016).
} 
saying that whenever there is moral thought emotion must be present at the same time and that, therefore, dispassionate moral thought is not possible. But, again, on the view I am advancing, moral thought is distinct from the emotion that serves as its categorical basis, and this creates space for the possibility of dispassionate moral thought. In particular, notice that on the view I propose, the emotions that underlie the behavioral dispositions involved in moral thought need not always be present when we have the behavioral dispositions in question. Suppose I am disposed to give to charity in virtue of the distress I undergo when I see people suffering hardship. Underlying this behavioral disposition is an emotion, then. But, although the behavioral disposition has an emotion as its basis, it need not be the case I undergo the emotion whenever I have the behavioral disposition. This is because my being disposed to give to charity entails only that I undergo distress when I perceive people suffering hardship, and we can suppose that for much of the time I am not perceiving anyone to be suffering hardship. Therefore, although the behavioral disposition has an emotion as its basis, I can have the behavioral disposition when I am not undergoing the emotion, and it is in this respect that dispassionate moral thought is possible, commonplace even.

The final objection takes the form of another counter-example to the idea that emotion has an important role in the formation of moral thought. A recent study found that psychopaths are more likely than non-psychopaths to make utilitarian judgments in situations involving committing of "personal harms' (Koenigs et al., 2012). Although non-psychopaths tend to regard as permissible diverting a trolley away from five innocents resulting in the death of another innocent, they are less likely to regard as permissible the pushing of an innocent in front of a trolley with the same aim of minimising loss of life. Psychopaths, on the other hand, tend to view both acts as permissible. One plausible explanation is that unlike other people, psychopaths are not averse to the causing of harm, and instead make moral judgments that comport with more utilitarian considerations. And if that is the case, then some might take this to show that emotion is not needed for moral judgment after all. Indeed, some are likely to claim such findings support a 'dual-process' theory, according to which some moral judgments are prompted by emotion - aversion to pushing innocents in front of trolleys, for instance - and others are the outputs of more deliberative cognitive processes (see Greene, 2007; Koenigs et al., 2012).

Now, there is a legitimate question as to whether psychopaths in this study were making utilitarian judgments. In particular, it is unclear how we can rule out altogether the possibility that psychopaths simply took pleasure in, or were wholly indifferent to, the idea of innocents being actively killed, and it was this fact about their emotional make-ups that explained why psychopaths thought the killing of innocents to be permissible in trolley cases. ${ }^{19}$ Indeed, in another study lack of empathic concern was perceived a likely reason for why psychopaths judged accidental harms less severely than non-psychopaths (Young et al., 2012), ${ }^{20}$ and the idea that pleasure elicited by harm or cruelty can underlie moral thought is

\footnotetext{
${ }^{19} \mathrm{I}$ owe this point to an anonymous reviewer.

${ }^{20}$ The Young et al. study is just as interesting for what it might tell us about non-psychopaths, who tend to judge accidental harms more severely than psychopaths, despite these actions lying outside the control of those
} 
supported by a study that found positive emotion to be associated with abnormal judgments of people who are sadists (Trémolière and Djeriouat, 2016). But, let us suppose that the psychopaths in the Koenigs et al. study were making utilitarian judgments. Would this show that emotion is not needed for moral thought? In light of the argument of this paper, I think we can see why this idea of a moral judgment that doesn't have a basis in emotion is clearly erroneous. For even if it is the case that people sometimes make moral judgments informed by careful consideration of possible outcomes, the question still arises: in virtue of what does a person come to have the behavioral dispositions involved in these moral judgments? For again, there must be some intrinsic property of a person - some fact about their internal make-up or psychology - in virtue of which the person regards as permissible those actions they consider to be maximally beneficial, either for themselves or other people. And again, it is unclear what that property might be other than emotion. One idea, then, might be that a person regards as permissible the action they calculate to have favourable outcomes in virtue of taking pleasure in the idea of performing the action in question - the action sits very comfortably with them, so to speak. If this is right, then the difference between psychopaths and non-psychopaths would show not that emotion fails to be needed for moral thought, but only that the moral judgments that different people make can have their bases in different emotions. With regard to the study just described, for instance, we might surmise that whereas nonpsychopaths tend to form their moral judgments in virtue of the distress that the idea of committing harm causes them, psychopaths form their moral judgments in virtue of the pleasurable emotions they undergo after deliberating on the courses of action that will likely deliver maximally beneficial outcomes. ${ }^{21}$

\section{Concluding remarks}

We have an answer to the question of whether emotion plays an important role in the generation of moral thought. The answer I have advanced is that emotion plays an important role because emotion is the most promising candidate - indeed it turns out to be the only plausible candidate - for the categorical basis for the behavioral dispositions involved in moral thought. And it is worth summarising how we arrived at this view. In §2 I pointed out that if motivational internalism is true, then moral judgments are to be identified in whole or in part with behavioral dispositions. However, it is widely accepted that there has to be some intrinsic property of an object in virtue of which the object has its dispositional properties or powers. The question arises then: what in the case of ourselves might play the role of a categorical basis for our behavioral dispositions, including our moral judgments? Answering this question was the task of $\S 3$ and

performing them. Again, the likely reason for this finding, suggested by the study authors and wholly consistent with the idea that emotion acts as the categorical basis for moral thought, is that non-psychopaths find accidental harms less permissible because they respond with adverse emotion to victims' experience of harm.

${ }^{21}$ Which would be consistent with findings on non-psychopaths showing there to be a link between induction of positive emotion and increased moral utilitarianism (e.g. Strohminger et al., 2011). 
$\S 4$. In §3 I ruled out behavioral dispositions themselves serving as bases. I showed also why cognitive and perceptual representations are not suited to serve as categorical bases for our behavioral dispositions. Although such mental states are not themselves behavioral dispositions, they are better viewed as stimulus conditions for the manifestations of our behavioral dispositions. I ended $\S 3$ by considering the idea that underlying our behavioral dispositions might be some innate moral code. But, this idea was also rejected because it turns out that any such code would itself be a collection of behavioral dispositions and, therefore, not suited to act as a categorical basis. In $\S 4$ I spelt out the case for emotion being the best candidate for the categorical basis for moral thought and other behavioral dispositions. I pointed out that emotion's felt properties make emotion very well suited to serve as the categorical basis for moral thought. Moreover, I outlined a number of considerations that positively support the idea that emotions underlie moral thought and other behavioral dispositions, including emotion's ability to explain the universality and immediacy of moral thought. Finally, in $§ 5$ I showed how viewing emotion as the categorical basis is able to answer a number of objections to the idea that emotion plays a role in moral thought.

Of course, objections to motivational internalism will need addressing before we can say for sure that emotion plays a role in the formation of moral judgment. It might be remarked, though, that if it is the case that motivational externalism is true instead we would still need some categorical basis for people's behavioral dispositions to act in accordance with their moral judgments. And I take it that if externalism is true the basis could not be the moral judgment, because if externalism is true our moral judgments along with other cognitive and perceptual representations - will be nothing more than stimulus conditions for the manifestations of our behavioral dispositions. In that case, the search for a basis would be a search for that thing that explains why we are disposed to behave in some way in response to our moral judgments. And, again, for the reasons spelt out in this paper, I think emotion would be the only plausible candidate for the categorical basis. That is to say, we would have to hold we are disposed to behave in some way in response to making a moral judgment in virtue of undergoing emotion (for instance, in virtue of the anxiety or pleasure that awareness of the moral fact in question occasions in us). Motivational externalism, then, also needs emotion to do important explanatory work, and this would be a significant result regarding our understanding of moral behavior even if motivational internalism is false. Nevertheless, if motivational externalism is true the behavioral disposition would not be internal to the moral judgment, and, therefore, we would still be without reason to think that emotion is involved in the formation of moral thought.

\section{Acknowledgments}

I am grateful to two anonymous reviewers and audience members in Lisbon, Hull, and Göttingen for their very helpful comments. 


\section{References}

Aharoni, E., Sinnott-Armstrong, W., and Kiehl, K. (2012). Can psychopathic offenders discern moral wrongs? A new look at the moral/conventional distinction. Journal of Research in Personality, 121, 484497.

Aquino, K., McFarren, B., and Laven, M. (2011). Moral identity and the experience of moral elevation in response to acts of uncommon goodness. Journal of Personality and Social Psychology, 100, 703-718.

Ashwell, L. (2014). The metaphysics of desire and disposition. Philosophy Compass, 9, 469-477.

- (2017a). Introspection and the nature of desire. In J. Deonna and F. Lauria (eds.) The Nature of Desire (pp. 325 336). Oxford: Oxford University Press.

- (2017b). Conflicts of desires: Dispositions and the metaphysics of mind. In J. Jacobs. (ed.), Causal powers (pp. 167-176). Oxford: Oxford University Press.

Audi, P. (2012). A clarification and defense of the notion of grounding. In F. Correia and B. Schnieder (eds.), Metaphysical grounding: Understanding the structure of reality (pp. 101-121). Cambridge: Cambridge University Press.

Bjornsson, G, Bjorklund, F, Strandberg, C, Eriksson, J, and Francen, R. (2015). Motivational internalism. Oxford: Oxford University Press.

Blackburn, S. (1998). Ruling passions. Oxford: Oxford University Press

Blair, R. (1995). A cognitive developmental approach to morality: Investigating the psychopath. Cognition, 57, 1-29.

Blair, R., Jones, L., Clark, F., and Smith, M. (1997). The psychopathic individual: A lack of responsiveness to distress cues?. Psychophysiology, 34, 192-198.

Brink, D. (1989). Moral realism and the foundations of ethics. Cambridge: Cambridge University Press. Bromwich, D. (2016). Motivational internalism and the challenge of amoralism. European Journal of Philosophy. 24, 452-471.

Chalmers, D. (2010). The character of consciousness. Oxford: Oxford University Press.

Choi, S and Fara, M. (2014). Dispositions. In The Stanford Encyclopedia of Philosophy (Spring 2014 Edition), E. Zalta (ed.), URL = <http://plato.stanford.edu/archives/spr2014/entries/dispositions/>.

Cima, M., Tonnaer, F., and Hauser, M. (2010). Psychopaths know right from wrong but don't care. Social Cognitive and Affective Neuroscience, 5, 59-67.

Cleckley, H. (1941). The mask of sanity: An attempt to reinterpret the so-called psychopathic personality. St Louis, Mo.: The C. V. Mosby Company

Cushman, F. (2008). Crime and punishment: Distinguishing the roles of causal and intentional analyses in moral judgment. Cognition, 108, 353-380.

Damasio, A. (1994). Descartes' error. New York: Quill

Dolan, M., and Fullam, R. (2010). Moral / conventional transgression distinction and psychopathy in conduct disordered adolescent offenders. Personality and Individual Differences, 49, 995-1000. 
Doris, J. and Stich, S. (2007). As a matter of fact: empirical perspectives on ethics. In F. Jackson and M. Smith (eds.). The Oxford handbook of contemporary philosophy (pp. 114-152). Oxford: Oxford University Press.

Dwyer, S. (2009). Moral dumbfounding and the linguistic analogy: Implications for the study of moral judgment. Mind \& Language 24, 274-296.

Fine, K. (2001). The Question of Realism. Philosophers' Imprint, 1, 1-30.

Goldberg, J, Lerner, J., Tetlock, P. (1999). Rage and reason: the psychology of the intuitive prosecutor. European Journal of Social Psychology, 29, 781-795.

Greene, J. (2007). Why are VMPFC patients more utilitarian? A dual-process theory of moral judgment explains. Trends in Cognitive Sciences, 11, 322-23.

Greene, J., and Haidt, J. (2002). How (and where) does moral judgment work? Trends in Cognitive Sciences, 6, 517-523.

Greene, J., Sommerville, R., Kystrom, L., Darley, J., Cohen, J., (2001). An FMRi investigation of emotional engagement in moral judgment, Science, 293, 2105-2108.

Haidt, J. (2001). The emotional dog and its rational tail. Psychological Review, 108, 814-834.

Hare, R. (1952). The language of morals. Oxford: Oxford University Press.

Harman, G. (2000). Explaining value and other essays in moral philosophy. New York: Oxford University Press

Hauser, M. (2006). Moral minds. New York: Harper Collins.

Horberg, E., Oveis, C., Keltner, D., and Cohen A. (2009). Disgust and the moralization of purity. Journal of Personality and Social Psychology, 97, 963-976.

Horgan, T., and Timmons, M. (2000). Nondescriptivist cognitivism: framework for a new metaethic. Philosophical Papers, 29, 121-53.

House T., Milligan W. (1976) Autonomic responses to modelled distress in prison psychopaths. Journal of Personality and Social Psychology, 34, 556-560.

Huebner, B., Dwyer, S., and Hauser, M. (2009). The role of emotion in moral psychology. Trends in Cognitive Sciences, 13, 1-6.

Hyman, J. (2014). Desires, dispositions and deviant causal chains. Philosophy, 89, 83-112.

James, W. (1884). What is an emotion? Mind, 9, 188-205.

Jenkins, C. (2011). Is metaphysical grounding irreflexive? Monist, 94, 267-276.

Koenigs, M., Kruepke, M., Zeier, J., and Newman, J. (2012). Utilitarian moral judgment in psychopathy. Social Cognitive and Affective Neuroscience, 7, 708-14.

Lowe, E. (2008). Personal agency: The metaphysics of mind and agency. Oxford, Oxford University Press.

May, J. (2014). Does disgust influence moral judgment? Australasian Journal of Philosophy, 92, 125141.

Mayr, E. (2011). Understanding human agency. Oxford: Oxford University Press. 
Mele, A. (1996). Internalist moral cognitivism and listlessness. Ethics, 106, 727-753.

McDowell, J. (1979). Virtue and reason. Monist, 62, 331-350.

McNaughton, D. (1988). Moral vision. Oxford: Blackwell.

Mikhail, J. (2007). Universal moral grammar: theory, evidence and the future. Trends in Cognitive Sciences, 11, 143-152.

Morse, S. (2008). Psychopathy and criminal responsibility. Neuroethics, 1, 205-212.

Nagel, T. (1970). The Possibility of Altruism. Oxford: Oxford University Press.

Nichols, S. (2002). How Psychopaths Threaten Moral Rationalism: Is it Irrational to Be Amoral? Monist, $85,285-303$.

- (2005). Innateness and moral psychology. In P. Carruthers, S. Laurence and S. Stich. (eds.) The Innate Mind. Structure and Contents. Oxford: Oxford University Press.

Pastötter, B., Gleixner, S., Neuhauser, T. and Bäuml, K. (2013). To push or not to push? Affective influences on moral judgment depend on decision frame. Cognition, 126, 373-377.

Prinz, J. (2004). Gut Reactions: A perceptual theory of emotion. Oxford: Oxford University Press.

— (2007). The emotional construction of morals. Oxford: Oxford University Press.

Prior, E., Pargetter, R. and Jackson, F., (1982). Three theses about dispositions. American Philosophical Quarterly, 19, 251-257.

Ridge, M. (2006). Ecumenical expressivism: finessing Frege. Ethics, 116, 302-336.

Russell, B. (1927). The Analysis of Matter. London: Kegan Paul.

Schaffer, J. (2009). On what grounds what. In D. Chalmers, D. Manley and R. Wasserman. (eds.) Metametaphysics. Oxford: Oxford University Press

Schnall, S., Haidt, J., Clore, G., and Jordan, A. (2008). Disgust as embodied moral judgment. Personality and Social Psychology Bulletin, 34/8, 1096-1109.

Schroeder, T. (2015). Desire. In The Stanford Encyclopedia of Philosophy (Spring 2014 Edition), E. Zalta (ed.), URL $=\langle$ http://plato.stanford.edu/archives/sum2015/entries/desire/>.

Smith, M. (1994). The Moral Problem. Oxford: Blackwell.

Stalnaker, R. (1984). Inquiry. Cambridge, MA: MIT Press.

Strohminger N, Lewis R, Meyer D. (2011). Divergent effects of different positive emotions on moral judgment. Cognition, 119, 295-300.

Svavarsdottir, S. (1999). Moral cognitivism and motivation. The Philosophical Review, 108, 161-219

Tahko, T. (2015). An Introduction to Metametaphysics. Cambridge: Cambridge University Press.

Trémolière, B., and Djeriouat, H. (2016). The sadistic trait predicts minimization of intention and causal responsibility in moral judgment. Cognition, 146, 158-171.

Tresan, J. (2006). De dicto internalist cognitivism. Nous, 40, 143-165.

Valdesolo, P., and DeSteno, D. (2006). Manipulations of emotional context shape moral judgment. Psychological Science, 17, 476-477. 
Williams, N. (2011). Dispositions and the argument from science. Australasian Journal of Philosophy, 89, 79-90.

Wheatley, T. and Haidt, J. (2005). Hypnotically induced disgust makes moral judgments more severe. Psychological Science, 16, 780-784.

Whiting, D. (2011). The feeling theory of emotion and the object-directed emotions. European Journal of Philosophy, 19, 281-303.

- (2012). Are emotions perceptual experiences of value? Ratio, 25, 93-107.

Young, L., Koenigs, M., Kruepke, M., and Newman, J. (2012) Psychopathy increases perceived moral permissibility of accidents. Journal of Abnormal Psychology, 121, 659-667.

Zangwill. N. (2003). Externalist moral motivation. American Philosophical Quarterly, 40, 143-154. 